\title{
Aortopulmonary Window with Interrupted Aortic Arch and Pulmonary Artery Sling: Diagnosis by Echocardiography and Magnetic Resonance Imaging:
}

\author{
Case Report and Literature Review
}

\author{
EU-LEONG H. J. TEO, M.B.B.S., F.R.C.R.,* CAREN S. GOLDBERG, M.D., $\dagger$ \\ PETER J. STROUSE, M.D., ${ }^{*}$ ROGER P. VERMILION, M.D., $\dagger$ \\ and EDWARD L. BOVE, M.D. \\ *Section of Pediatric Radiology, Department of Radiology, †Section of Pediatric Cardiology, \\ Department of Pediatrics and Cummunicable Diseases, and \$Section of Pediatric Thoracic \\ Surgery, Department of Surgery, C. S. Mott Children's Hospital, University of Michigan Health \\ System, Ann Arbor, Michigan
}

We present the pediatric case of a patient who had aortopulmonary window with interrupted aortic arch, intact ventricular septum, and pulmonary artery sling that was imaged with echocardiography and magnetic resonance imaging. This case is unique because this combination of findings has not been previously reported. The diagnosis was made without the need for angiography, and the findings were confirmed at surgery. This case shows that complex congenital heart defects can be accurately imaged by noninvasive methods. (ECHOCARDIOGRAPHY, Volume 16, February 1999)

aortopulmonary window, interrupted aortic arch, pulmonary artery sling, children, congenital heart disease, magnetic resonance imaging

In recent years, echocardiography and Doppler echocardiography have advanced to the point that many children with complex congenital heart disease no longer require invasive imaging before surgical management. Concomitantly, magnetic resonance imaging (MRI) has advanced in its ability to delineate complex congenital cardiac anatomy. ${ }^{1}$

In this report, we describe a patient with an unusual combination of three uncommon congenital cardiac anomalies who was successfully diagnosed by echocardiography and

Address for correspondence and reprint requests: Peter J. Strouse, M.D., Section of Pediatric Radiology, C.S. Mott Children's Hospital, University of Michigan Health System, 200 East Hospital Drive, Ann Arbor, MI 48109-0252. Fax: 734-764-9351.
MRI, obviating the need for invasive presurgical evaluation.

\section{Case Report}

The patient was the product of a full-term pregnancy. His birth weight was $2.55 \mathrm{~kg}$, and he was discharged on the third day after delivery. The father detected increasing cyanosis and tachypnea at 1 week of age, and the primary care physician referred the patient to our institution for further evaluation.

On physical examination, the infant weighed $2.78 \mathrm{~kg}$, with a pulse rate of 180 beats $/ \mathrm{min}$, respiratory rate of 44 , and blood pressures of $84 / 49,79 / 51,78 / 42$, and $62 / 38 \mathrm{mmHg}$ in the right arm, left arm, right leg, and left leg, respectively. The radial and femoral pulses were $2+$ and $1+$, respectively. The baby was cya- 
notic. The liver edge was $3 \mathrm{~cm}$ below the costal margin. Auscultation revealed normal first and second heart sounds, and no murmur was detected. The lungs were clear to auscultation with normal breath sounds. No stridor was present. The electrocardiogram revealed tachycardia at 188 beats/min but was otherwise normal. Oxygen saturation at room air was $60 \%$. The blood gas results with the infant on 2 liters of oxygen via nasal cannula revealed $\mathrm{pH} 7.42$; $\mathrm{PCO}_{2}, 42 \mathrm{mmHg} ; \mathrm{PO}_{2}, 46 \mathrm{mmHg}$; and bicarbonate, $24 \mathrm{mEq} /$ liter. A chest radiograph showed mild cardiomegaly and normal pulmonary vascular markings.

Two-dimensional echocardiography revealed a large aortopulmonary window at the junction of the main pulmonary artery and right pulmonary artery (Fig. 1A). The aortic arch was found to be interrupted beyond the origin of the left subclavian artery (Fig. 1B). At the time of the initial echocardiogram, the ductus arteriosus, although patent, was restrictive; it subsequently increased in size with prostaglandin therapy. The left pulmonary artery originated from the midright pulmonary artery and coursed posterior to the trachea (Fig. 1B). A moderate-sized secundum atrial septal defect was demonstrated with bidirectional shunting. The ventricular septum was intact. The right ventricle was dilated and poorly contractile, whereas the left ventricular ejection fraction was $53 \%$.

To confirm the echocardiographic findings, MRI of the heart was performed using T1weighted spin-echo and fast-gradient recalled echocardiography with cardiac-triggered segmented acquisition (FASTCARD; GE Medical Systems, Milwaukee, Wis) sequences in axial, coronal, and sagittal planes. Although MRI confirmed the findings of echocardiography (Fig. 2), it did not contribute any additional information.

The patient underwent corrective surgery on the basis of the echocardiographic and MRI findings without the need for angiography. The preoperative findings were confirmed during the operation. Primary resection and end-toend anastomosis of the interrupted aortic arch were performed. The left pulmonary artery was transected a few millimeters distal to its origin on the right pulmonary artery and anasto-
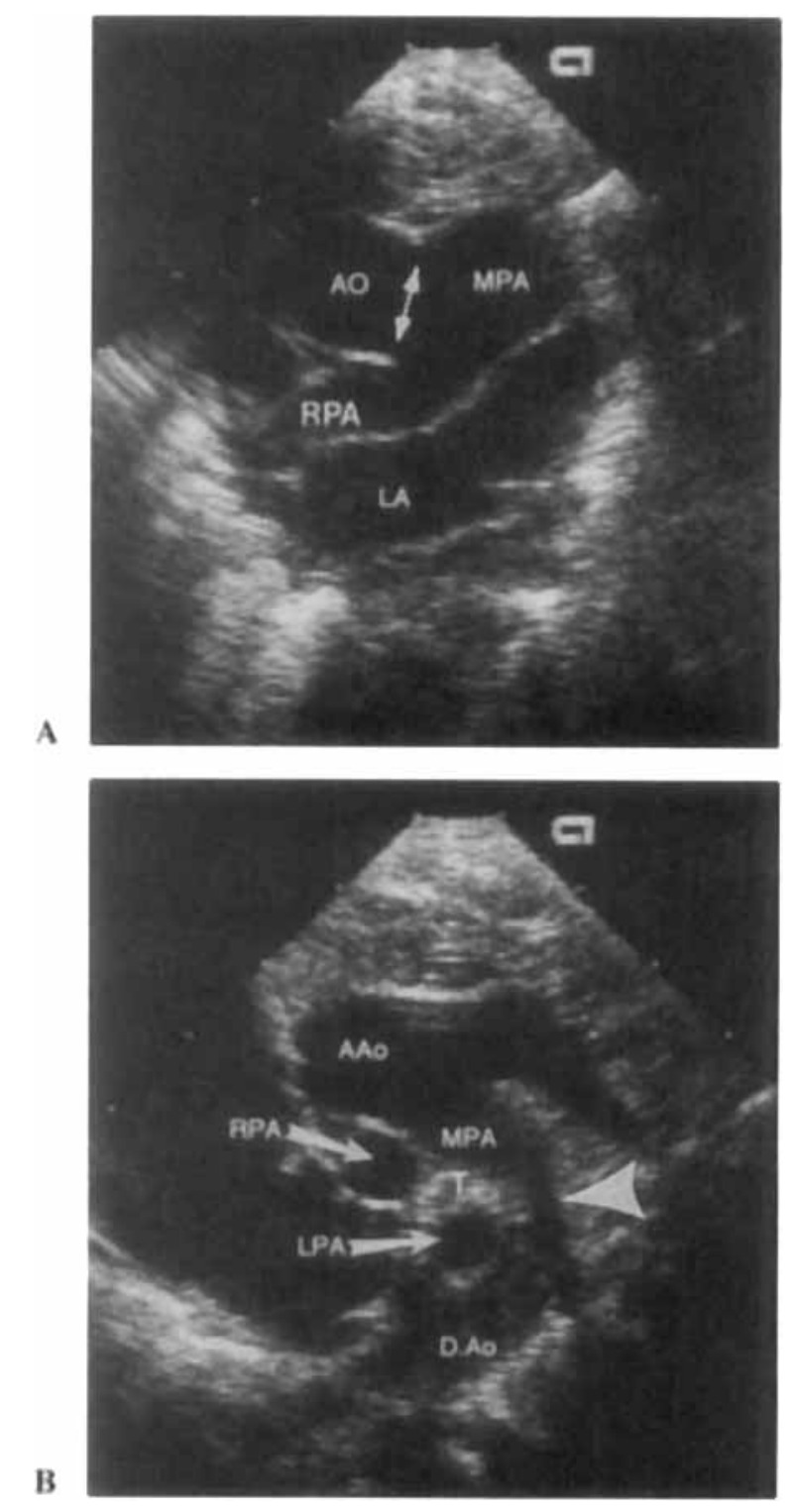

Figure 1. Echocardiography. (A) Suprasternal notch coronal view. The aortopulmonary window (double-headed arrow) is demonstrated connecting the ascending aorta (AO) to the main pulmonary artery (MPA) just proximal to the takeoff of the right pulmonary artery (RPA). The left atrial appendage is prominent in this view to the left of the MPA. LA = left atrium. (B) Suprasternal notch sagittal view. The main pulmonary artery (MPA) and descending aorta (D.Ao) are connected by the patent ductus arteriosus (arrowhead). Posterior to the ascending aorta is the right pulmonary artery (RPA) and the unusually positioned left pulmonary artery (LPA) as it passes posterior to the trachea (T). AAo = ascending aorta. 
A
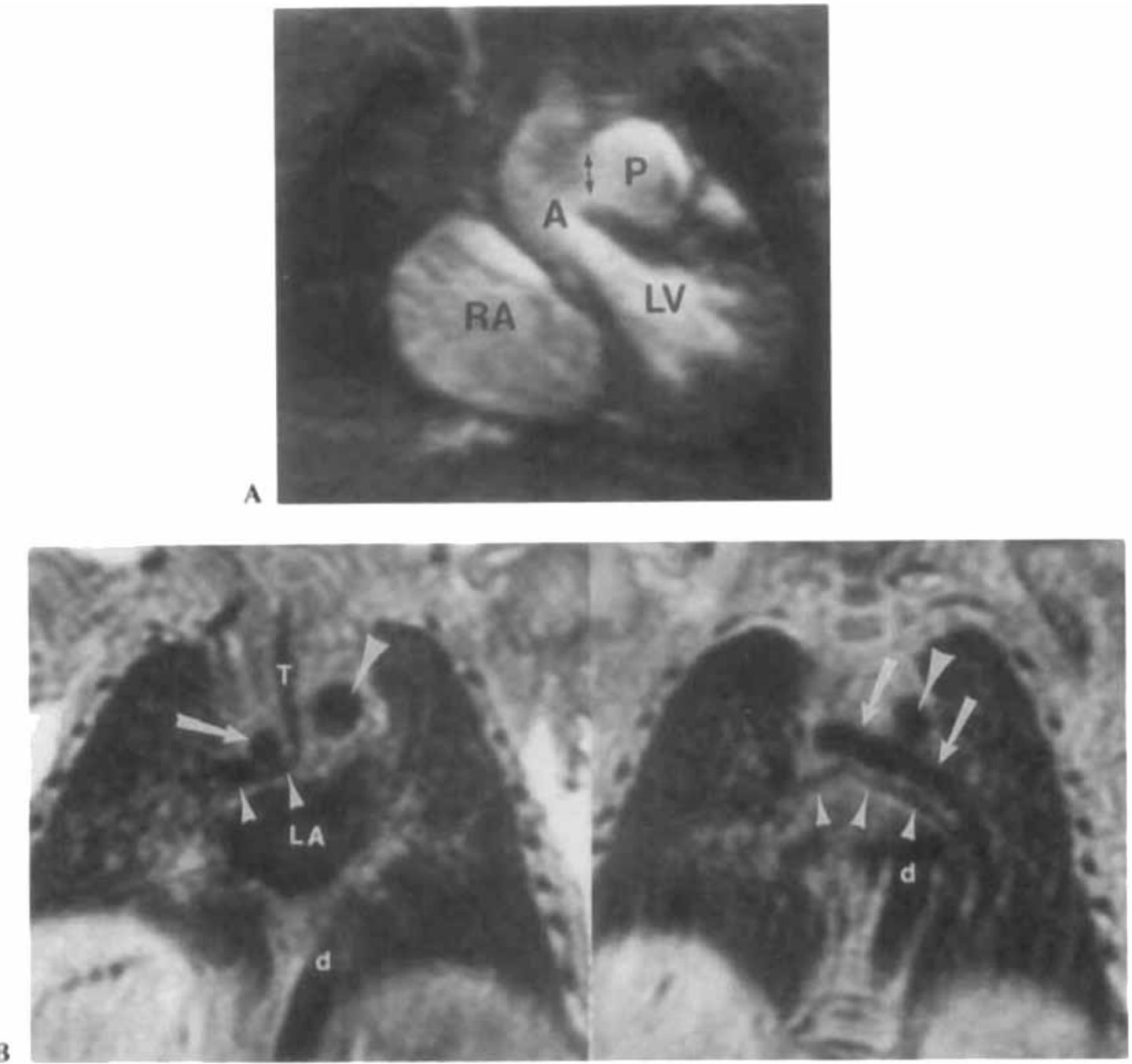

Figure 2. Magnetic resonance imaging. (A) Aortopulmonary window. Coronal gradient echo image (TR 13.6 $\mathrm{msec}$, TE $5.4 \mathrm{msec}, 30^{\circ}$ flip angle). The aortopulmonary window (double-headed arrow) is seen as a large communication between the aorta $(A)$ and the main pulmonary artery $(P) . L V=$ left ventricle, $R A=$ right atrium. (B) Pulmonary sling. Coronal T1-weighted spin echo images (TR $500 \mathrm{msec}, T E 16 \mathrm{msec}$ ). (Left) The anomalous left pulmonary artery (arrow) to the right of the trachea (T), coursing above right mainstem bronchus (small arrowheads). (Right) A more posterior image showing the anomalous left pulmonary artery (arrow) coursing across the mediastinum to the left hilum. Note the classic inverted " $T$ " orientation of the trachea ( $T$, left) and mainstem bronchi (small arrowheads). The origin of left pulmonary artery from right pulmonary artery was well demonstrated on axial images. $d=$ descending aorta, $L A=$ left atrium, large arrowhead $=$ patent ductus arteriosus.

mosed to the main pulmonary trunk anterior to the trachea. The aortopulmonary window was opened anteriorly and closed with a patch of polytetrafluoroethylene (Gore-Tex; W.L. Gore Associates, Flagstaff, Ariz). The atrial septal defect also was closed.

\section{Discussion}

Aortopulmonary window is a rare form of congenital heart disease, accounting for $\sim 0.2 \%$ of all cardiac defects. ${ }^{2}$ The defect is thought to result from incomplete fusion of the truncal 
ridges, with a resultant persistent communication between the ascending aorta and main pulmonary artery. Associated cardiovascular anomalies are seen in more than half of all cases. ${ }^{2,3}$ An associated interrupted aortic arch is present in 13\%, and tetralogy of Fallot is present in $6 \% .^{2}$

Interrupted aortic arch also is a rare anomaly, occurring in $1.4 \%$ of infants with congenital heart disease. ${ }^{4}$ The defect probably results from regression of both the left and right embryonic aortic arches. In studies by CollinsNakai et al. ${ }^{4}$ and Menahem et al., ${ }^{5}$ interrupted aortic arch was always associated with other congenital cardiac anomalies. Approximately one third of patients had ventricular septal defect with patent ductus arteriosus, one third had a complex ventricular septal defect with left ventricular outflow obstruction, and one third had complex intracardiac lesions (usually including a ventricular septal defect) incompatible with survival at the time of reporting, which was $1976 .{ }^{4}$ No cases were reported in association with a pulmonary artery sling.

Pulmonary artery sling is postulated to originate from a failure of normal left pulmonary artery development with persistent embryonic vascular supply from the right side. Associated cardiovascular anomalies are seen in approximately half of reported cases of pulmonary artery sling. ${ }^{6}$ The most common associated anomalies are patent ductus arteriosus, atrial septal defect, persistent left superior vena cava, and ventricular septal defect.
The combination of anomalies seen in this patient is heretofore unreported. The embryological relationship of aortopulmonary window, interrupted aortic arch, and pulmonary artery sling in this patient is uncertain. The three anomalies were all prospectively diagnosed by echocardiography with MR confirmation. These noninvasive imaging results, in conjunction with physical examination findings and blood gas results, allowed for reparative surgery without the need for invasive angiography in this infant.

\section{References}

1. Hernandez RJ, Aisen AM, Foo TKF, et al: Thoracic cardiovascular anomalies in children: Evaluation with a fast gradient-recalled-echo sequence with cardiac-triggered segmented acquisition. Radiology 1993;188:775-780.

2. Kutsche LM, Van Mierop LH: Anatomy and pathogenesis of aorticopulmonary septal defect. Am J Cardiol 1987;59:443-447.

3. Tiraboschi R, Salomone G, Crupi G, et al: Aortopulmonary window in the first year of life: A report on 11 surgical cases. Ann Thorac Surg $1988 ; 46: 436-441$.

4. Collins-Nakai RL, Dick M, Parisi-Buckley L, et al: Interrupted aortic arch in infancy. $J$ Pediatr 1976;88:959-962.

5. Menahem S, Rahayoe AU, Brawn WJ, et al: Interrupted aortic arch in infancy: A 10-year experience. Pediatr Cardiol 1992;13:214-221.

6. Yeager SB, Chin AJ, Sanders SP: Two-dimensional echocardiographic diagnosis of pulmonary artery sling. J Am Coll Cardiol 1986;7:625-629. 